\title{
Outbreak of unusual H2S-negative monophasic Salmonella Typhimurium strain likely associated with small tomatoes, Sweden, August to October 2019
}

Soledad Colombe ${ }^{1,2}$, Cecilia Jernberg ${ }^{1}$, Emma Löf $^{1}$, Anna Lindqvist Angervall ${ }^{3}$, Henrik Mellström-Dahlgren ${ }^{3}$, Leif Dotevall ${ }^{3}$, Malin Bengnér ${ }^{4}$, Ingela Hall ${ }^{4}$, Lena Sundqvist ${ }^{1}$, Sharon Kühlmann-Berenzon ${ }^{1}$, Ilias Galanis ${ }^{1}$, Mats Lindblad ${ }^{5}$, Anette Hansen ${ }^{1}$, Moa Rehn ${ }^{1}$ 1. Public Health Agency of Sweden, Solna, Sweden

2. European Programme for Intervention Epidemiology Training (EPIET), European Centre for Disease Prevention and Control (ECDC), Solna, Sweden

3. County Council Department of Communicable Disease Control and Prevention, Region Västra Götaland, Gothenburg, Sweden

4. County Council Department of Communicable Disease Control and Prevention, Region Jönköping, Jönköping, Sweden

5. Swedish Food Agency, Uppsala, Sweden

Correspondence: Soledad Colombe (soledad.colombe@folkhalsomyndigheten.se)

Colombe Soledad, Jernberg Cecilia, Löf Emma, Angervall Anna Lindqvist, Mellström-Dahlgren Henrik, Dotevall Leif, Bengnér Malin, Hall Ingela, Sundqvist Lena, Kühlmann-Berenzon Sharon, Galanis Ilias, Lindblad Mats, Hansen Anette, Rehn Moa. Outbreak of unusual H2S-negative monophasic Salmonella Typhimurium strain likely associated with small tomatoes, Sweden, August to October 2019. Euro Surveill. 2019;24(47): pii=1900643. https://doi.0rg/10.2807/1560-7917.

ES.2019.24.47.1900643

Sweden is investigating an outbreak of monophasic Salmonella Typhimurium. Eighty-two nationallydistributed cases have been confirmed, with date of symptom onset between 28 August and 29 October. Cases were 51 years of age on average (range: $0-89$ ) and the majority of cases were female $(62 \%)$. A casecontrol study was conducted and suggested small tomatoes as source of the outbreak (adjusted odds ratio (OR): $10.8,95 \%$ confidence interval $(\mathrm{Cl})$ : $4.15-$ 112.68, p value $<0.001$ ), and a trace-back investigation led to a single, non-Swedish producer in Europe. Both the Salmonella strain and the source of the outbreak are rarely encountered in Europe. Results from investigation at the producer are pending.

\section{Background}

Salmonellosis is one of the most common food-borne pathogen in the European Union (EU), with 90,000 cases reported annually [1]. In Sweden, clinical and laboratory diagnoses of Salmonella infection are notifiable by law. Around 2,000 cases are reported annually, the majority being infected abroad [2]. Sweden has Salmonella control programs in place for feed, animals and food products of animal origin, and Swedish meat and eggs are generally free from Salmonella [3].

Monophasic Salmonella Typhimurium is among the most common serovars in Europe, including in Sweden, with sequence type (ST)34 being the most common sequence type [4]. It is historically known to be commonly transmitted by pork products [4]. Although incubation time can be 6 to 72 hours for Salmonella, it has been shown that the median incubation period range for $95 \%$ of Salmonella Typhimurium outbreaks is 12 to 192 hours [5].

\section{Outbreak detection}

On 10 September 2019, the County Council Department of Communicable Disease Control and Prevention (CDC-department) in Jönköping informed the Public Health Agency of Sweden (PHAS) of the detection of five domestic cases of Salmonella with no obvious epidemiological connection over the 2 days prior. This was not only an uncommon accumulation of cases, but all had also been caused by an unusual Salmonella strain phenotypically shown to be hydrogen sulfide $\left(\mathrm{H}_{2} \mathrm{~S}\right)$ negative on traditional growth agar medium, i.e. the characteristic black pigmentation of the colonies was lacking. Then on 11 September 2019, the CDC-department in Västra Götaland reported a sixfold increase in domestic Salmonella group B cases compared with the same time period over the last 4 years. On 12 September, a small cluster of seven monophasic Salmonella Typhimurium ST3478 was identified among isolates from across the country. Isolates were identified as part of the routine microbial surveillance program where all isolates of Salmonella from domestic infection are sent to PHAS for further typing using whole genome sequencing (WGS). On 17 September, the cluster had grown to 27 isolates and an outbreak was declared at the national level, with an investigation initiated to describe the outbreak and identify the source of infection. The outbreak team included PHAS, the Swedish Food Agency (SFA), the CDC-departments and the municipalities' environmental health departments. Eighty-two nationally-distributed cases were confirmed, with date of symptom onset between 28 
Number of confirmed cases, by date of symptom onset/sampling, timeline of the monophasic Salmonella Typhimurium outbreak investigation, Sweden, August-October $2019(\mathrm{n}=82)$

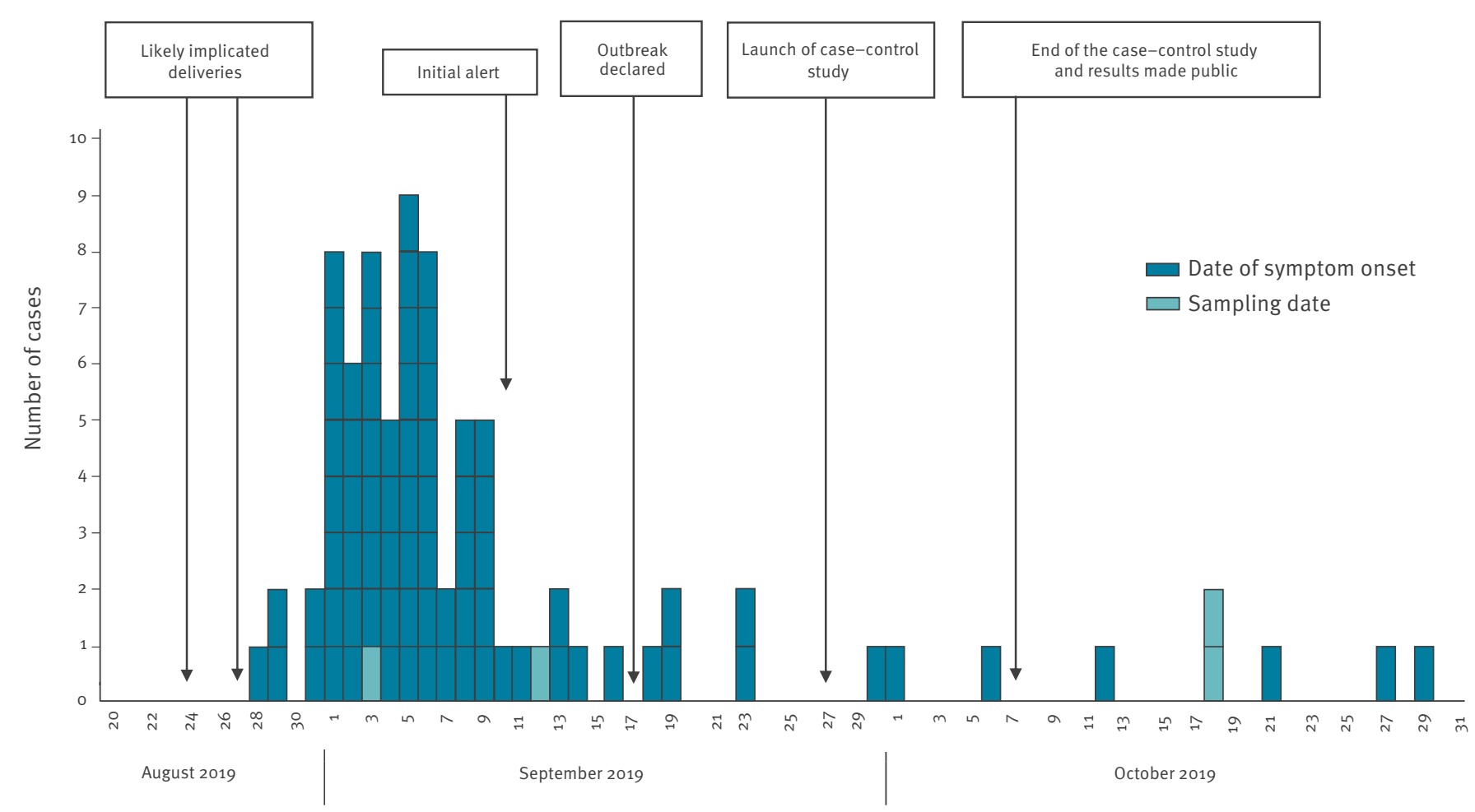

Date of symptom onset or sampling date ${ }^{a}$

a Date of symptom onset was replaced by sample date if date of symptom onset was missing.

August and 29 October. The following report describes the outbreak investigation until 18 November 2019.

\section{Methods}

\section{Outbreak case definition}

A suspected case was defined as a case with a laboratory result matching the unusual phenotype of the Salmonella strain, infected in Sweden according to the clinician, and notified after 15 August 2019 since the earliest reported date of symptom onset was 28 August 2019. A case was confirmed if it belonged to the outbreak WGS cluster of monophasic Salmonella Typhimurium ST3478.

\section{Epidemiological investigation}

Data on age, sex, county of residence, date of symptom onset and sample date were collected via the national system for notifiable diseases. Date of symptom onset was replaced by sample date if date of symptom onset was missing. An initial trawling questionnaire, set for a recall period of 7 days and asking general questions about the consumption of foods known to be potential sources for Salmonella, was sent to cases by email. If cases did not have an email address or were too sick to access the online questionnaire, it was administered on paper via regular mail or by telephone interviews.

\section{Case-control study}

We further investigated the source of the outbreak by conducting a case-control study. From a national random pool of controls $(n=5,900)$ available at PHAS [6], we selected 384 controls. These controls were matched on age group, sex and county of residence to each of the first 48 cases of the outbreak ( 8 controls per case). Some of the first 48 cases of the outbreak never filled in the case-control questionnaire. Since more cases were confirmed after the start of the case-control study, new cases were also included in the analysis if they had answered the case-control questionnaire. A general description of the potential source of the outbreak was made public to address public concern on 7 October 2019 and cases confirmed after that date were not included in the study. In total, 45 of 71 confirmed cases up to 7 October 2019 answered the case-control questionnaire and were thus included in the analysis, regardless if they had initially been matched to controls or not. Only 29 of 45 cases were matched to controls, 
Percentage exposed among cases and controls, odds ratio and adjusted odds ratio of cases compared with controls in monophasic Salmonella Typhimurium outbreak investigation, Sweden, August-October 2019 ( $\mathrm{n}=45$ cases)

\begin{tabular}{|c|c|c|c|c|c|c|c|c|c|c|}
\hline \multirow[t]{2}{*}{ Food item or retail company } & \multicolumn{2}{|c|}{$\begin{array}{l}\text { Cases } \\
\text { exposed } \\
(n=45)^{a}\end{array}$} & \multicolumn{2}{|c|}{$\begin{array}{l}\text { Controls } \\
\text { exposed } \\
(n=328)^{a}\end{array}$} & \multicolumn{3}{|c|}{ Model for each exposure ${ }^{b}$} & \multicolumn{3}{|c|}{ Final model ${ }^{c}$} \\
\hline & $n$ & $\%$ & $n$ & $\%$ & OR & $95 \% \mathrm{Cl}$ & $\mathrm{p}$ value & AdjOR & $95 \% \mathrm{Cl}$ & $p$ value \\
\hline Small tomatoes & 44 & 98 & 173 & 53 & 10.1 & $3.94-103 \cdot 41$ & $<0.001$ & 10.8 & $\begin{array}{c}4.15^{-} \\
112.68\end{array}$ & $<0.001$ \\
\hline $\begin{array}{l}\text { Grocery shopping at a retail store } \\
\text { belonging to Company } A\end{array}$ & 37 & 82 & 117 & 36 & 7.8 & $3.75-19.80$ & $<0.001$ & 8.5 & $\begin{array}{l}3.95^{-} \\
22.41\end{array}$ & $<0.001$ \\
\hline Grilled chicken from store $^{d}$ & 14 & 31 & 31 & 10 & 2.9 & $1.67-4.93$ & $<0.001$ & NA & NA & NA \\
\hline Nectarines & 11 & 24 & 48 & 15 & 1.6 & $0.88-2.58$ & 0.10 & NA & NA & NA \\
\hline Cucumbers & 35 & 78 & 211 & 66 & 1.5 & $0.93-2.76$ & 0.10 & NA & NA & NA \\
\hline Large tomatoes & 26 & 58 & 147 & 45 & 1.4 & $0.92-2.27$ & 0.11 & NA & NA & NA \\
\hline $\begin{array}{l}\text { Grocery shopping at a retail store } \\
\text { belonging to Company B }\end{array}$ & 7 & 16 & 39 & 12 & 1.4 & $0.52-3.13$ & 0.44 & NA & NA & NA \\
\hline Smoked ham & 26 & 58 & 151 & 47 & 1.4 & $0.87-2.16$ & 0.17 & NA & NA & NA \\
\hline Grapes & 18 & 40 & 105 & 33 & 1.3 & $0.79-1.97$ & 0.32 & NA & NA & NA \\
\hline Bell pepper & 22 & 49 & 135 & 42 & 1.2 & $0.78-1.90$ & 0.39 & NA & NA & NA \\
\hline $\begin{array}{l}\text { Grocery shopping at a retail store } \\
\text { belonging to Company C }\end{array}$ & 14 & 31 & 103 & 31 & 1.0 & $0.49-1.94$ & 0.97 & NA & NA & NA \\
\hline $\begin{array}{l}\text { Grocery shopping at retail stores } \\
\text { belonging to other companies }\end{array}$ & 4 & 9 & 32 & 10 & 1.0 & $0.26-2.58$ & 0.99 & NA & NA & NA \\
\hline Carrots & 23 & 51 & 183 & 58 & 0.8 & $0.53-1.32$ & 0.44 & NA & NA & NA \\
\hline Apples & 16 & 36 & 145 & 46 & 0.7 & $0.46-1.17$ & 0.20 & NA & NA & NA \\
\hline $\begin{array}{l}\text { Grocery shopping at a retail store } \\
\text { belonging to Company D }\end{array}$ & 3 & 7 & 42 & 13 & 0.6 & $0.11-1.53$ & 0.31 & NA & NA & NA \\
\hline $\begin{array}{l}\text { Grocery shopping at a retail store } \\
\text { belonging to Company E }\end{array}$ & 25 & 56 & 242 & 74 & 0.4 & $0.23-0.85$ & 0.01 & NA & NA & $\mathrm{NA}$ \\
\hline
\end{tabular}

adjOR: adjusted odds ratio; $\mathrm{Cl}$ : confidence interval; NA: not applicable; OR: odds ratio.

a Only cases and controls responding to the case-control study questionnaires are included.

${ }^{b}$ Each exposure adjusted for sex and age group (0-17 years, 18-59 years, 6o years and above).

c Adjusted for sex, age group (0-17 years, 18-59 years, 60 years and above) and the one other exposure in the model.

d The final model did not include grilled chicken as exposure among cases was low.

and as the number of matched case control pairs was not sufficient to perform a matched analysis, we conducted an unmatched analysis. Controls were excluded if they had travelled abroad during the recall period or reported symptoms compatible with salmonellosis, i.e. diarrhoea and either of fever, abdominal pain or bloody diarrhoea.

The case-control questionnaire that was sent to both cases and controls included those food items from the trawling questionnaire that had been consumed by more than $40 \%$ of the cases, and asked if the consumed vegetables and fruits were organic or non-organic, and details about retail stores they did their general grocery shopping at. The recall period was set to 7 days before symptom onset (cases) or before answering the questionnaire (controls).

We conducted unmatched Firth logistic regression [7] adjusting for age group and sex, both when including individual exposures in the model as well as when including multiple exposures. We calculated odds ratios (OR), their 95\% confidence interval $(95 \% \mathrm{Cl})$ and $\mathrm{p}$ values for models including individual exposures, and adjusted odds ratios (adjOR), $95 \% \mathrm{Cl}$ and $\mathrm{p}$ values for models including multiple exposures. The latter were built by step-wise backward selection, starting with a full model including all items with an exposure among cases $>40 \%$, a $p$ value $\langle 0.2$ and an $O R>1$ in the individual exposure model, and removing food items one-by-one based on Akaike information criterion (AIC) improvement. The threshold for significance was set at 0.05 .

\section{Microbiological investigations of human isolates}

The local clinical microbiological laboratories cultured and isolated Salmonella from submitted faecal samples. Colonies lacking the black pigmentation on Xylose-Lysine-Deoxycholate (XLD) and DeoxycholateCitrate (DC) agar plates, i.e. $\mathrm{H}_{2} \mathrm{~S}$ negative, leaving the colonies light pink, were defined as the suspected outbreak strain. 
Percentage exposed among cases and controls and adjusted odds ratio of exposures among those who ate small tomatoes in the monophasic Salmonella Typhimurium outbreak investigation, Sweden, August-October 2019 ( $\mathrm{n}=44$ cases)

\begin{tabular}{|c|c|c|c|c|c|c|c|}
\hline \multirow{2}{*}{ Exposure } & \multicolumn{2}{|c|}{ Cases exposed $(n=44)$} & \multicolumn{2}{|c|}{ Controls exposed $(n=173)$} & \multirow{2}{*}{$\operatorname{adjOR}^{\mathrm{a}}$} & \multirow{2}{*}{$95 \% \mathrm{Cl}$} & \multirow{2}{*}{$\mathrm{p}$ value } \\
\hline & $\mathrm{n}$ & $\%$ & $\mathrm{n}$ & $\%$ & & & \\
\hline Small organic tomatoes & 26 & 59 & 47 & 27 & 2.5 & $1.22-6.14$ & 0.017 \\
\hline Small non-organic tomatoes & 22 & 50 & 111 & 64 & 1.3 & $0.59-3.05$ & 0.56 \\
\hline Retail store belonging to Company A & 37 & 84 & 57 & 33 & 9.0 & $3.87-28.91$ & $<0.001$ \\
\hline
\end{tabular}

adjOR: adjusted odds ratio; $\mathrm{Cl}$ : confidence interval.

${ }^{a}$ Adjusted for other exposures presented in the table, age group (0-17 years, 18-59 years and 60 years or above) and sex.

Multilocus sequence typing (MLST) at PHAS and subsequent ST was calculated by mapping the raw reads to a reference sequence for each loci of the EnteroBase Salmonella 7-gene MLST scheme. Single nt polymorphisms (SNPs) were called based on an assembly of one of the outbreak strains using CLC Assembly Cell version 4.4.2 (Qiagen Bioinformatics, Hilden, Germany), minimum 10x coverage, $90 \%$ read consensus. Minimum spanning trees were generated using MSTgold [8] and recombinations were filtered by looking for SNPs with a pairwise distance of $500 \mathrm{nt}$. One representative outbreak sequence was deposited to the European Nucleotide Archive (ENA) (https://www. ebi.ac.uk/ena), number ERR3577233. For the sequence submitted to ENA, the MiSeq instrument (Illumina, San Diego, California, United States) was used [9].

\section{Trace-back investigation and microbiological analysis of food}

Based on the outcome of the epidemiological investigation, the SFA conducted a trace-back investigation of the food source and retail company. Information on the likely date of purchase was collected from seven cases with an onset of disease early in the outbreak, and the product was traced back to the producer.

Leftover suspected food source was collected from two cases and analysed for Salmonella spp. at commercial laboratories.

\section{Results}

\section{Descriptive epidemiology}

A total of 82 cases were notified and confirmed by WGS, with date of symptom onset between 28 August 2019 and 29 October 2019. Cases were distributed between 12 of 21 counties in Sweden, with the majority of cases occurring in the south-western part of the country $(67 \%, n=55)$. Cases had a mean age of 51 years (range: $0-89)$ and were mostly female $(62 \%$, $n=51)$.

The distribution of date of symptom onset suggested a point source outbreak, with a common food source having a short shelf-life (Figure 1).
A total of 40 cases (50\%) responded to the trawling questionnaire. Of the 40,38 reported having eaten tomatoes within the incubation period, and at least seven cases reported the same type and brand of tomatoes.

\section{Case-control study}

Response rates to the case-control study questionnaires were 45 of 71 (63\%) among cases and 328 of 384 (85\%) among controls. Controls resided in the same counties as cases and one additional county, and had a mean age of 54 years (range: $1-88$ ). Of controls, $62 \%$ $(n=202)$ were female. Logistic regressions for each of the 16 exposures (Table 1 ) showed that small tomatoes, grilled chicken from the store and shopping at retail stores belonging to Company $A$, a nation-wide food retailer owning different retail chains, were associated with being a case (Table 1). The final multivariable model included both small tomatoes (OR:10.8, 95\% Cl: 4.15-112.68, $\mathrm{p}<0.001$, percentage exposed among cases: $98 \%$ ) and grocery shopping at company A (OR: $8.5,95 \% \mathrm{Cl}: 3.95-22.41, \mathrm{p}<0.001$, percentage exposed among cases: $82 \%$ ). The final model did not include grilled chicken as exposure among cases was low (31\%).

For those who had eaten small tomatoes $(n=44)$, small organic tomatoes and grocery shopping from Company A were associated with being a case (Table 2 ).

We further stratified the analysis on those that shopped from company $A$ and those that did not. Among those who had eaten small tomatoes and bought their groceries from Company $A(n=37)$, small organic tomatoes (OR: 2.7, 95\% Cl: 1.23-7.20, p value 0.021) were associated with being a case, while small non-organic tomatoes were not (OR: 0.9, 95\% Cl: 0.36-2.17, p value 0.73). For those who did not shop from company $A$, interpretation was difficult because of a very small number of cases $(n=6)$ : small non-organic tomatoes (OR: 7.90, 95\% Cl: 0.78-Infinite, p value 0.091) and small organic tomatoes (OR: $2.55,95 \% \mathrm{Cl}: 0.26-17.53$, p value 0.29 ). 
Minimum spanning tree of monophasic Salmonella Typhimurium isolates from domestic cases, Sweden, 1 January-31 October 2019

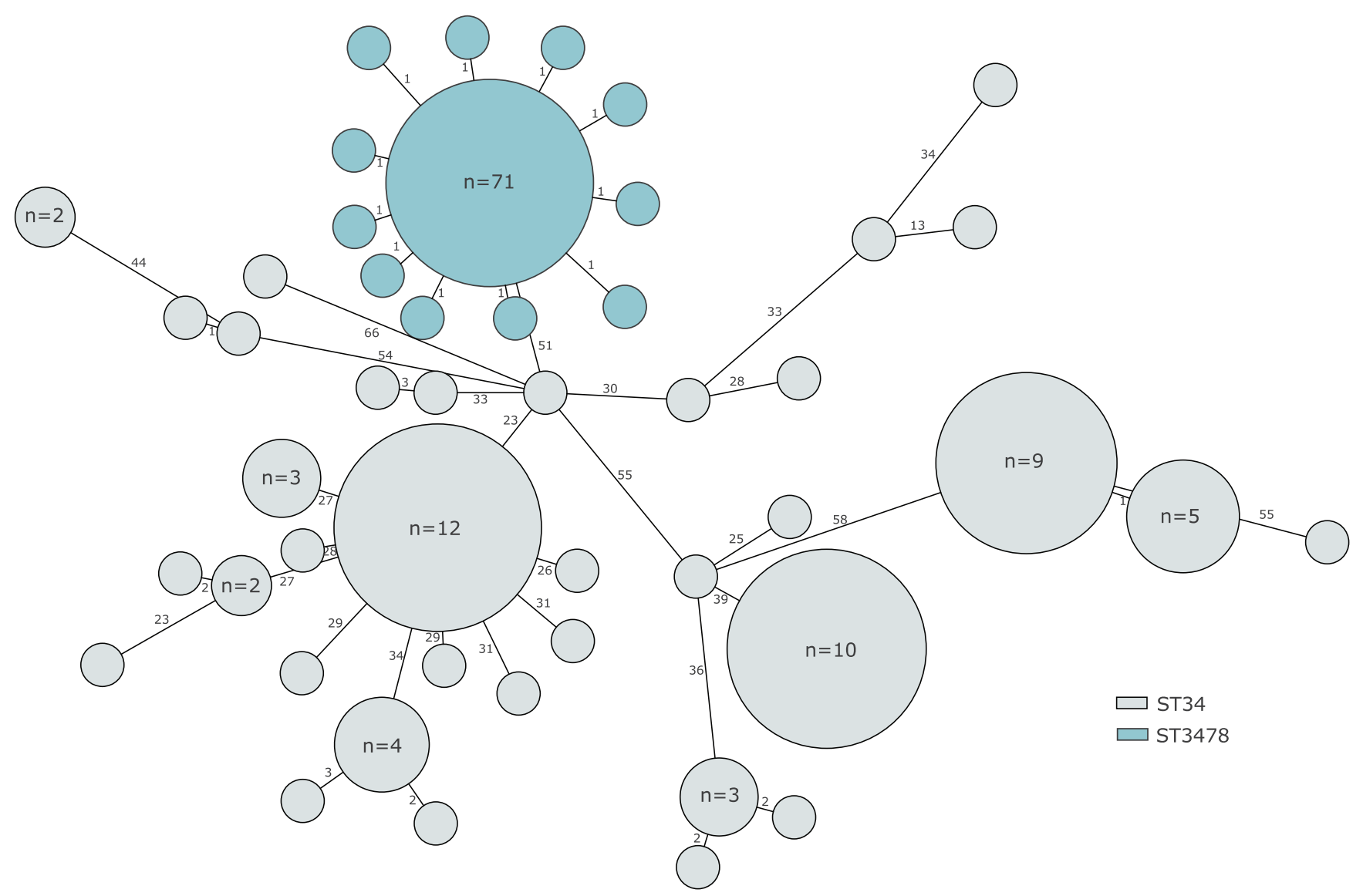

The common strain of $76, \mathrm{ST}_{34}$ is shown in grey while the outbreak strain, $\mathrm{ST} 3478$, is shown in blue. SNP differences are shown next to the branches. The length of the branches are not proportional to the SNP distances. The Minimum spanning tree was generated using MSTgold [2] and recombinations were filtered by looking for SNPs with a pairwise distance of $500 \mathrm{nt}$.

\section{Descriptive microbiology of human isolates} All isolates clustered with o-2 SNP differences, and were identified as monophasic Salmonella Typhimurium, ST3478, which is similar to the more commonly encountered ST34 (Figure 2). All isolates were $\mathrm{H}_{2} \mathrm{~S}$ negative, which is a rare phenotypic feature among Salmonella strains regardless of serotype.

\section{Trace-back investigation and microbiological analysis of food}

All small organic tomatoes sold at Company A's retail stores were delivered by one wholesaler in Sweden and sold under the private label of Company A. Deliveries at the end of August and the beginning of September showed that the product was produced and packed by one company in an EU country. Small organic tomatoes bought by cases within a few days before symptom onset most likely originated from either or both of two deliveries arriving to Sweden on 24 and 27 August 2019. Products from these deliveries were sold across the country.
No leftover small tomatoes available from cases' households were from the suspected deliveries. Two samples from other deliveries were nonetheless analysed for Salmonella spp., with negative results. No grilled chicken was tested for.

\section{Outbreak control measures}

On 19 September, PHAS decided to inform all local clinical microbiological laboratories in Sweden about the unusual phenotypic characteristic of the outbreak strain to enable faster identification of cases and to ensure that the strain was not missed. On 7 October 2019, the possibility of small tomatoes being the source of the outbreak was published on PHAS' website with general advice on how to prevent infection with Salmonella, and stating that the contaminated tomatoes were unlikely to still be on the market [10].

On 19 September, PHAS also contacted and shared a representative outbreak sequence (Ion Torrent data) with public health institutes in Denmark, Finland, Norway, neighbouring countries with an awareness of challenges regarding comparing lonTorrent data and 
Illumina data, and the United Kingdom, which does SNP analysis on a routine basis for an initial sequence comparison. None of these countries found a matching sequence. On 3 October 2019, an urgent inquiry (UI603) was posted on the European Centre for Disease Prevention and Control (ECDC) Epidemic Intelligence Information System for Food and Waterborne Diseases and Zoonoses (EPIS-FWD), to enquire about cases in other European countries. According to responses to the urgent inquiry in EPIS from nine countries until 21 October 2019, this specific ST had only been seen in the past in only a few sporadic cases.

On 11 October, the SFA informed the competent authority in the country of the producer of the small organic tomatoes and the results of the follow up are pending. No recall was performed because tomatoes from the implicated deliveries were no longer on the market.

\section{Discussion}

This is the first reported outbreak of Salmonella in Sweden with small tomatoes as the likely source of infection and only the second in Europe [11], despite tomatoes being a well-known source of Salmonella outbreaks in the United States [12-14]. The results from this investigation highlight the importance of considering vegetables as a possible vector of pathogens traditionally thought to be associated with animal products $[15,16]$. Despite not being able to sample the implicated batches of tomatoes for analysis of Salmonella, the epidemiological link to small tomatoes was strong. Samples from potential cases are still being analysed by WGS. Two more cases were confirmed on 13 November 2019 and investigation regarding their exposures is ongoing.

The main analysis pointed towards small tomatoes as the likely source. Our subset analysis suggested that small organic tomatoes specifically might be the main source, but organic tomatoes only explained $60 \%$ of cases. This discrepancy could be explained by recall bias or by contamination of small non-organic tomatoes at the producer. Local media coverage after the start of the case-control study could have also biased the late answers of controls, reducing the estimate of the $O R$.

Grilled chicken was not considered to be a true risk factor for being a case in our outbreak as the exposure among cases was low. In addition, the chicken is grilled directly in the supermarket and it would be unlikely that supermarkets from across the country undercooked and improperly stored their grilled chicken over the same time period.

ST3478 has been rarely seen in Europe thus far, yet we observed an outbreak with over 80 cases. We can only speculate on the reasons why Sweden was the sole country affected by this outbreak. One possibility could be that just a few batches were contaminated and all of them were sent to Sweden. Another possibility is that because the strain lacked the black pigmentation on traditional growth agar medium, it could have been missed in other countries. Countries should be aware that this ST in combination with its unusual phenotypic feature $\left(\mathrm{H}_{2} \mathrm{~S}\right.$-negative) could go unnoticed on traditional growth agar medium because of the lack of black pigmentation. It underlines the importance of a close collaboration between clinical laboratories, food laboratories and offices for control of communicable diseases in identifying and investigating outbreaks.

\section{Acknowledgements}

We would like to acknowledge all the outbreak team members that made this outbreak investigation possible at the County Council Departments of Communicable Disease Control and Prevention of Dalarna, Gävleborg, Halland, Jönköping, Kronoberg, Stockholm, Södermanland, Västra Götaland, Västernorrland, Örebro, and Östergötland, at PHAS and at SFA, as well as environmental investigators at the municipality level. Nadja Karamehmedovic, Ingela Hedenström and Anneli Rasmusson at PHAS for typing of the Salmonella isolates. Rikard Dryselius at PHAS for his contribution to the investigation and insightful comments on the manuscript. The Hälsorapport team for helping set up the case-control study and recruiting controls. The cases and controls that took the time to answer the questionnaires. The doctors, nurses and clinical microbiological laboratories at the local level for allowing rapid detection of the outbreak and of cases.

\section{Conflict of interest}

None declared.

Authors' contributions

SC, CJ, EL, AL, HM, LD, MB, IH, LS, SK, IG, ML, AH, and MR were part of the outbreak investigation team and contributed to the implementation of the case control study. In addition, $A L, H M, L D, M B$, and IH sent the initial alerts and contributed to the investigation at the local level. $\mathrm{AH}$ and MR coordinated the investigation at the national level. SC, EL, SK, IG, and MR designed the case-control study. SC analyzed data from the case-control study, supported by EL, SK, IG and MR. CJ coordinated the laboratory investigations. ML led the traceback investigation. SC drafted the manuscript. SC, CJ, EL, $A L, H M, L D, M B, I H, L S, S K, I G, M L, A H$, and MR contributed to the revision of the draft manuscript and approved the final version.

\section{References}

1. European Food Safety Authority (EFSA). EFSA explains zoonotic diseases. Salmonella. Parma: EFSA; 2014. Available from: https://www.efsa.europa.eu/sites/default/files/corporate_ publications/files/factsheetsalmonella.pdf

2. Public Health Agency of Sweden (PHAS). Salmonellainfektion. [Salmonella infection]. Solna: PHAS. [Accessed 18 Nov 2019]. Swedish. Available from: https://www.folkhalsomyndigheten. se/folkhalsorapportering-statistik/statistik-a-o/ sjukdomsstatistik/salmonellainfektion/?t=c

3. Swedish National Veterinary Institute (SVA). Salmonella as a zoonosis. Uppsala: SVA. [Accessed 18 Nov 2019]. Available from: https://www.sva.se/en/animal-health/zoonoses/ salmonella-as-a-zoonosis

4. Biswas S, Li Y, Elbediwi M, Yue M. Emergence and Dissemination of mcr-Carrying Clinically Relevant Salmonella Typhimurium Monophasic Clone ST34. Microorganisms. 2019;7(9):298. https://doi.org/10.3390/ microorganisms7090298 PMID: 31466338 
5. Chai SJ, Gu W, O’Connor KA, Richardson LC, Tauxe RV. Incubation periods of enteric illnesses in foodborne outbreaks, United States, 1998-2013. Epidemiol Infect. 2019;147:e285. https://doi.org/10.1017/So950268819001651 PMID: 31587689

6. Public Health Agency of Sweden (PHAS). Hälsorapport - a webbpanel. [Hälsorapport- a web panel]. Solna: PHAS. [Accessed 18 Nov 2019]. Swedish. Available from: https://www. folkhalsomyndigheten.se/folkhalsorapportering-statistik/ om-vara-datainsamlingar/halsorapport/

7. Pearce N. Analysis of matched case-control studies. BMJ. 2016;352:i969. https://doi.org/10.1136/bmj.i969 PMID: 26916049

8. Salipante SJ, Hall BG. Inadequacies of minimum spanning trees in molecular epidemiology. J Clin Microbiol. 2011;49(10):3568 75. https://doi.org/10.1128/JCM.00919-11 PMID: 21849692

9. Söderlund R, Jernberg C, Trönnberg L, Pääjärvi A, Ågren E, Lahti E. Linked seasonal outbreaks of Salmonella Typhimurium among passerine birds, domestic cats and humans, Sweden, 2009 to 2016. Euro Surveill. 2019;24(34). https://doi. org/10.2807/1560-7917.ES.2019.24.34.1900074 PMID: 31456557

10. Public Health Agency of Sweden (PHAS). Trolig källa till utbrott av salmonella funnen. [Findings on the probable source of the outbreak of Salmonella]. Solna: PHAS; 7 Oct 2019. [Accessed 15 Oct 2019]. Swedish. Available from: https://www.folkhalsomyndigheten. se/nyheter-och-press/nyhetsarkiv/2019/oktober/ trolig-kalla-till-utbrott-av-salmonella-funnen

11. Müller L, Kjelsø C, Frank C, Jensen T, Torpdahl M, Søborg B, et al. Outbreak of Salmonella Strathcona caused by datterino tomatoes, Denmark, 2011. Epidemiol Infect. 2016;144(13):2802 11. https://doi.org/10.1017/S0950268816000121 PMID: 26846608

12. Gurtler JB, Harlee NA, Smelser AM, Schneider KR. Salmonella enterica Contamination of Market Fresh Tomatoes: A Review. J Food Prot. 2018;81(7):1193-213. https://doi.org/10.4315/0362028X.JFP-17-395 PMID: 29965780

13. Bennett SD, Littrell KW, Hill TA, Mahovic M, Behravesh CB. Multistate foodborne disease outbreaks associated with raw tomatoes, United States, 1990-2010: a recurring public health problem. Epidemiol Infect. 2015;143(7):1352-9. https://doi. org/10.1017/S0950268814002167 PMID: 25167220

14. Alsanius B. Landskapsarkitektur, Trädgård.

Växtproduktionsvetenskap - Rapportserie. Hygien och bevattningsvatten. Rapport 2014:10. [Landscape planning and gardens. Plant production science - Report series. Hygiene and irrigation water. Report 2014:10]. Alnarp: Sveriges lantbruksuniveritet (SLU); 2014. [Accessed 15 Oct 2019]. Swedish. Available from: https://pub.epsilon.slu.se/11327/7/ alsanius_b_140627_2.pdf

15. Berger CN, Sodha SV, Shaw RK, Griffin PM, Pink D, Hand P, et al. Fresh fruit and vegetables as vehicles for the transmission of human pathogens. Environ Microbiol. 2010;12(9):238597. https://doi.org/10.1111/j.1462-2920.2010.02297.x PMID: 20636374

16. Vojkovská H, Myšková P, Gelbíčová T, Skočková A, Koláčková I, Karpíšková R. Occurrence and characterization of foodborne pathogens isolated from fruit, vegetables and sprouts retailed in the Czech Republic. Food Microbiol. 2017;63:147-52. https://doi.org/10.1016/j.fm.2016.11.012 PMID: 28040162

\section{License, supplementary material and copyright}

This is an open-access article distributed under the terms of the Creative Commons Attribution (CC BY 4.0) Licence. You may share and adapt the material, but must give appropriate credit to the source, provide a link to the licence and indicate if changes were made.

Any supplementary material referenced in the article can be found in the online version.

This article is copyright of the authors or their affiliated institutions, 2019. 